\title{
CONDITION MONITORING OF RAILWAY TRACK SYSTEMS BY USING ACCELERATION SIGNALS ON WHEELSET AXLE-BOXES
}

\author{
Andrzej Chudzikiewicz ${ }^{1}$, Roman Bogacz ${ }^{2,3}$, Mariusz Kostrzewski ${ }^{1}$, Robert Konowrocki ${ }^{3}$ \\ ${ }^{1}$ Faculty of Transport, Warsaw University of Technology, Poland \\ ${ }^{2}$ Faculty of Automotive and Construction Machinery Engineering, Warsaw University of Technology, Poland \\ ${ }^{3}$ Institute of Fundamental Technological Research, Polish Academy of Science, Warsaw, Poland
}

Submitted 12 August 2016; resubmitted 21 October 2016; accepted date 18 January 2017; published online 04 September 2017

\begin{abstract}
The aim of this paper is to demonstrate the possibilities of estimating the track condition using axle-boxes and car-bodies motions described by acceleration signals. In the paper, the results presented indicate the condition of tracks obtained from the preliminary investigation on the test track. Furthermore, the results from the supervised runs (on Polish Railway Lines) of Electric Multiple Unit (EMU-ED74) with the prototype of track quality monitoring system installed on-board are described. As Track Quality Indicator (TQI) algorithm, used in the mentioned prototype, a modified Karhunen-Loève transformation is used in preliminary preparation of acceleration signals. The transformation is used to extract the principal dynamics from measurement data. Obtained results are compared to other methods of evaluating the geometrical track quality, namely methods, which apply the synthetic coefficient $J_{\text {synth }}$ and five parameters of defectiveness $W_{5}$. The results from the investigation showed that track condition estimation is possible with acceptable accuracy for in-service use and for defining cost-effective maintenance strategies.
\end{abstract}

Keywords: railway track monitoring; wheel/rail interaction; track quality indicator; acceleration signals; experimental investigation; track degradation.

\section{Introduction}

In order to prevent dangerous occurrences, that may take place during operation of mechanical structures and devices and in order to predict the impact of potential defects on their further operation, there is a necessity of a constant monitoring of technical condition of mechanical structures and constant development of more precise and reliable testing methods or systems. Such approach and research aim at preventing human losses, material damage, ecological disasters and costeffective maintenance of engineering structures. Over last few decades railway vehicle dynamics has changed from being fundamental mechanical engineering discipline to one that utilises sensors, electronics devices and computer processing. Furthermore, this fact affects track condition monitoring as well.

Railway tracks worldwide are important factor in providing an efficient transportation system; therefore their maintenance and renewal are cost consuming. Railway operators conduct periodic inspections of their track infrastructure in order to maintain safe and efficient service. In addition to internal railroad inspection procedures, periodic track inspections are required under track safety standards of the International Union of Railways (UIC) and the Federal Railroad Administration (FRA). The objective of presented investigations is a demonstration of a developed track monitoring system, which makes track inspection more efficient and effective (RST Instruments 2014; Metrom Rail 2016; DGSI 2016). Such systems are needed, because a railway vehicle and track interactions during services generate substantial forces on railway tracks (Bogacz, Konowrocki 2012; Bogacz et al. 2014). Such forces are transient by nature and of relatively large magnitude and are also related to impact railway vehicle loading which cause degradation of the track and reduction of safety. Considering vehicle/track interactions, which consist of vibrations of a railway vehicle elements caused by a vehicle passage on a flexible track, should be taken into consideration in track monitoring. The vibration coupling of the two sub-systems (track and vehicle) is

Corresponding author: Mariusz Kostrzewski

E-mail: markos@wt.pw.edu.pl 
being caused by wheel/rail contact forces. The escalation of such vibrations is rising mainly due to rails surface imperfections, such as rail roughness, corrugation or defects on a rolling contact surface of rail track. All these vehicle/track interactions can be examined in condition monitoring of tracks. Several approaches to estimation of track condition by measuring the acceleration of the elements of railway testing vehicles are available. One of the methods of track condition monitoring is measurement of instantaneous acceleration signals. Weston et al. (2007) showed that several kinds of track faults can be detected by measuring the acceleration of railway vehicle bogies. Molodova et al. $(2011,2014)$ most of all focused on method for detecting squats on a rail track surface. In this method, axle-boxes acceleration measurements are taken into consideration and the quantitative relationship between characteristics of accelerations and rail track defects are specified. Tsunashima et al. (2012) and Mori et al. (2010) proved that track defects can be detected in the cabin of railway vehicle. Distinctive signals of track's faults are hidden in natural frequencies of car body vibrations, while a railway vehicle is in-service. Zhai et al. (2015) precisely discussed data gained from the tests of high-speed trains passing on the non-ballasted track. They analysed not only axel-boxes acceleration but also tested wheel profile wear, using single on-board measuring system. Kojima et al. (2006) developed a method to detect track faults based on accelerations measurement and use of discrete wavelet transformations. This method detects faults by breaking down the measurement signal into an approximation component of low frequency and a detailed component of high frequency. Huang et al. (2013) and Yu et al. (2014) presented fibre optic technology for detection of rail corrugation, based on fibre-laser accelerometers. The authors have used a principle of detection of rail corrugation using double integration of axle-box accelerations. High sensitivity and large dynamic range have been achieved by using fibre optic interferometric demodulation. Continuous monitoring, supervision and inspection of railway tracks using the fibre optic were discussed also by Naderi and Mirabadi (2006). Other authors discussed yet another approach to evaluate the quality of railway tracks based on wheel/rail dynamics (Glösmann, Kreuzer 2006; Konop, Konowrocki 2013). These authors analysed wheel-set dynamics of underground and classic railway vehicles using KarhunenLoève transformation to extract the principal dynamics from measurement data. Oukhellou et al. (1999) after Montandon and Mager (1984) presented the system based on a specialised eddy-current sensor for the inspection of railway tracks. Their approach is used to detect broken rails and large head spalls of the rail. Lee et al. (2012) described a method of estimating irregularities in railway tracks using acceleration data measured from high-speed railway vehicles. Their method is based on a mixed-filtering approach, which consists of the three types of filters: Kalman filter for displacement estimation, band pass filter for waveband classification, and compensation filter for amplitude and phase compensation. Stenström et al. (2015) describe integrated approach to monitoring of different ways of operations and maintenances of rail infrastructure systems and their components.

Apart from the academic approach to a track condition testing, also commercial approach and solutions should be mentioned. Both in literature and among practical technical solutions, stationary and non-stationary devices for track condition measurement are distinguished. In this case the authors will focus on non-stationary systems. The non-stationary devices BRSSOS Track Monitoring (BRSSOS Ltd. 2015) and T\&T Sistemi Railway Track Quality System (T\&T Sistemi srl. 2009) can be distinguished. These devices were designed to monitor a track in periods of operation and maintenance of rail routes. Such systems must be used especially on tracks where high-speed trains run. There are, to mention only some of many: a practical system called High-Speed Track Inspection Machine (HISTIM) which was installed as a part of an additional equipment of track recording and has been in operation on track geometry cars on Shinkansen bullet-train lines in Japan (Naganuma et al. 2008) and other systems: TRAck State Confirming (TRASC) machine (Naganuma, Sato 1999), TRack Information Processing System (TRIPS) - Sato, Miwa (2000), RAil ROughness (RARO) continuous measuring machine (Naganuma et al. 2008). Another system called RAIDARSS-3 was installed on Japanese high-speed trains Shinkansen, mentioned above, in order to continue vertical track irregularities check (Kobayashi et al. 2008; Tsunashima et al. 2011). The main aim of the system is to automatically send reports to a train control centre and track maintenance depots when measured accelerations exceed predetermined target values. Another stationary device is Weigh-in-Motion system. It consists of measurement stations situated along a track. Its theoretical background, simulation modelling and laboratory tests are precisely specified by Meli, Pugi (2013); Allotta et al. (2015) and D’Adamio et al. (2016). The experimental tests in a field test and in-service exploitation are scheduled according to mentioned authors.

The main focus of this paper is the estimation of certain physical parameters in a track condition monitoring system so as to provide an early warning in case of a fault or performance degradation, as well as to provide information to support condition-based maintenance of track in case of railway in-service vehicles use. Assessment of the track is made based on analysis of acceleration signals, whereby the measurements are made by accelerometers mounted on the bearings of wheel sets. In this approach, track condition is estimated from the vertical and lateral acceleration of axle-boxes. These signals are computed into Track Quality Indicator (TQI), which is described below.

The paper is organised as follows. In Section 1, a model of track quality rating is presented. In Section 2, the details of on-board measurement system are described. In Section 3, the field test results of track con- 
dition measurement in a test track are described and in Section 4, the in-service results are presented. The Sections 3 and 4 describe the condition monitoring system of a track. Finally, conclusive remarks and future research proposal are provided.

\section{Track Quality Indicators}

In order to evaluate the condition of a railway track, appropriate assessment techniques are used. At first, wellknown, up to date approaches to estimate track quality parameters are discussed below. Finally, a new approach to track condition evaluation which employs computing of TQI is described below.

\subsection{The Synthetic Track Quality Coefficient}

The synthetic coefficient $J_{\text {synth }}$ is used as an indicator of a track quality based on the standard deviation applied by Polish Railways (Madejski, Grabczyk 2002). The equation for calculating synthetic coefficient $J_{\text {synth }}$ has form as Eq. (1):

$$
J_{\text {synth }}=\frac{S_{z}+S_{y}+S_{w}+0.5 \cdot S_{e}}{3.5},
$$

where: $S_{z}, S_{y}, S_{w}$ and $S_{e}$ are the four track geometry parameters: $S_{z}$ - vertical irregularities, $S_{y}$ - horizontal irregularities, $S_{w}$ - track twist, and $S_{e}$ - track gauge. The standard deviation for each measured parameter is calculated by Eq. (2):

$$
S=\sqrt{\frac{1}{n} \cdot \sum_{i=1}^{n}\left(x_{i}-\bar{x}\right)^{2}} .
$$

Based on the Eq. (2), $n$ is identified as the number of signals registered on the track being analysed, $x_{i}$ represents the value of geometry parameters at point $i$ and $\bar{x}$ is the average value of the measured signals. The synthetic coefficient $J_{\text {synth }}$ also specifies the allowable deviation of synthetic coefficient $J_{\text {synth }}$ for different values of vehicle velocity (Table 1 ). If any values are exceeded, a remedial action is required to bring the track back to the appropriate quality level.

Table 1. Allowable deviations of track geometry synthetic coefficient $J_{\text {synth }}$ (Madejski, Grabczyk 2002)

\begin{tabular}{|l|c|c|c|c|c|c|c|c|}
\hline $\begin{array}{l}\text { Velocity } \\
{[\mathrm{km} / \mathrm{h}]}\end{array}$ & 80 & 100 & 120 & 140 & 160 & 180 & 200 & $220^{*}$ \\
\hline $\begin{array}{l}\text { Synthetic } \\
\text { coefficient } \\
J_{\text {synth }}[\mathrm{mm}]\end{array}$ & 7.0 & 5.5 & 4.9 & 2.8 & 2.0 & 1.6 & 1.4 & 1.1 \\
\hline
\end{tabular}

Note: ${ }^{*}$ calculated through extrapolation.

\subsection{Five Parameters of Defectiveness}

The five parameters of defectiveness are noted as $W_{5}$, which is a quality measure of line segments developed by the Polish Railways (Madejski 2004). The formula treats the defectiveness of each geometry parameter as an independent event in practice. Considering the ar- rangement of the parameters, the following formula is described by Eq. (3):

$$
\begin{aligned}
& W_{5}=1-\left(1-W_{e}\right) \cdot\left(1-W_{g}\right) \times \\
& \left(1-W_{w}\right) \cdot\left(1-W_{x}\right) \cdot\left(1-W_{y}\right),
\end{aligned}
$$

where: $W_{e}, W_{g}, W_{w}, W_{x}$ and $W_{y}$ respectively are: $W_{e}-$ defectiveness of track gauge, $W_{g}$ - defectiveness of cant, $W_{w}$ - defectiveness of twist, $W_{x}$ and $W_{y}$ are arithmetic averages for vertical and horizontal irregularities, respectively, as determined from the defectiveness of left and right rails. The coefficient of parameter defectiveness $W$ in the approach is calculated using the following Eq. (4):

$$
W=\frac{\sum_{i=1}^{n} l_{i}}{l},
$$

where: $W$ has to be substituted with $W_{e}, W_{g}, W_{w}, W_{x}$ and $W_{y}$ respectively; $l_{i}$ is a number of samples of assessment section which exceeded an allowed value of $W_{e}$, $W_{g}, W_{w}, W_{x}$ or $W_{y}$ respectively; $l$ is a total number of section samples, $n$ is a number of exceedances of allowed threshold for total measured section.

The five-parameter defectiveness is calculated based on the exceedances of the maximum allowed limit values. The qualification for line maintenance which depends on the defectiveness value is specified in Table 2 .

Table 2. Quality qualifications of track lines (Madejski, Grabczyk 2002)

\begin{tabular}{|c|c|c|c|c|}
\hline $\begin{array}{c}\text { Evaluation } \\
\text { of line }\end{array}$ & New & $\begin{array}{c}\text { Good } \\
\text { condition }\end{array}$ & $\begin{array}{c}\text { Sufficient } \\
\text { condition }\end{array}$ & $\begin{array}{c}\text { Indicating } \\
\text { insufficient } \\
\text { condition }\end{array}$ \\
\hline Value $W_{5}$ & $W_{5}<0.1$ & $W_{5}<0.2$ & $W_{5}<0.6$ & $W_{5}>0.6$ \\
\hline
\end{tabular}

\subsection{The Proposed TQI}

It should be emphasised, that track monitoring and track inspection are not the same thing. Inspection focuses on a track safety ensured by the use of a Track Recording Vehicle (TRV) or hauled Track Recording Coach (TRC) running around the rail network and gathering track geometry data. The synthetic coefficient $J_{\text {synth }}$ and the five parameters of defectiveness $W_{5}$ suffice to conduct track inspection. Meanwhile, monitoring - as it focuses on faults and supports efficient maintenance - requires continuous measurements (Weston et al. 2015). The TQI meets this expectation.

Algorithm proposed in the paper specifies the TQI as determined by inertial measurement. Inertial measurement is based on a simple law where double integration of acceleration indicates a position on an accelerometer. For example, a vertical position of a wheel can be computed by double integration of axle-box acceleration. The result provides the longitudinal level due to a wheel being continuously in contact with a rail (Fig. 1).

The authors decided to evaluate a track condition by means of utilising an acceleration signal recorded by sensors mounted on axle-boxes of rail vehicle wheel-sets. 


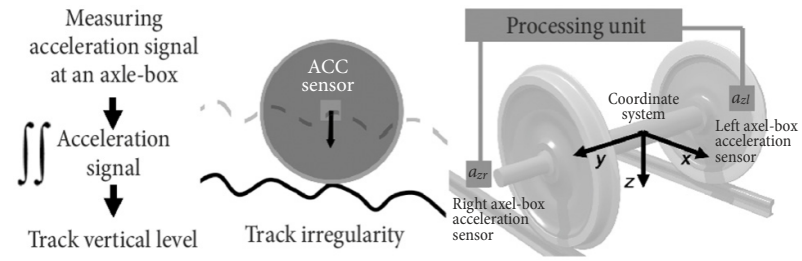

Fig. 1. Inertial track measurement at vertical level and application diagram

By analogy to the comfort index of a run of rail vehicles (Grzyb 1986), the general form of the indicator for the track condition assessment is suggested in the form of Eq. (5):

$$
W_{t_{-} g e n}=c_{t} \cdot\left(\int_{0}^{\infty} S_{a}(\omega) \cdot \omega^{b} d \omega\right)^{c},
$$

where: $c_{t}$ is constant value set on the basis of the numerical research; $S_{a}(\omega)$ is the spectral density of the recorded acceleration signal $a(t)$ (vector of filtered acceleration signal) while the rail vehicle moving with constant velocity and $b, c$ are constant values set on the basis of the numerical research. The $c_{t}$ value is suggested to be determined by method of trial and error in the way so that the $W_{t}$ index receives values from range between 0 and 5. Initial testing analysis of the $W_{t}$ TQI was carried out for the different types of indicators as described in paper (Bogacz et al. 2011). The analysis allowed to select the final form of the indicator described by the Eq. (6):

$$
W_{t}=c_{t} \cdot\left(\int_{0}^{\infty} S_{a}(\omega) \cdot \omega^{2} d \omega\right)^{0.15} .
$$

The initial tests showed that computing can be done without determining a spectral density of jerk function $S_{\dot{a}}(\omega)$ directly from the known function of derivative of acceleration with respect to time. The transformation is shown as Eq. (7):

$$
\begin{aligned}
& \int_{0}^{\infty} S_{a}(\omega) \cdot \omega^{2} d \omega=\int_{0}^{\infty} S_{\dot{a}}(\omega) d \omega= \\
& \pi \cdot \lim _{T \rightarrow+\infty}\left(\frac{1}{T} \cdot \int_{0}^{T} \dot{a}^{2}(t) d t\right) .
\end{aligned}
$$

Using the transformation (7), an equation can be obtained, in which the acceleration signal $a(t)$ can be

a)

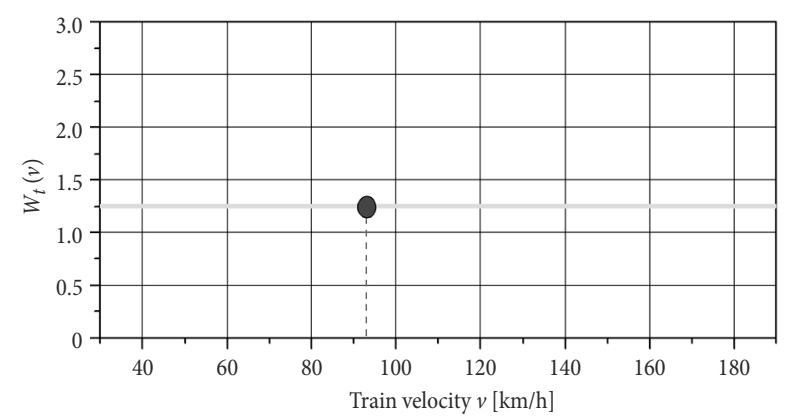

used directly to calculate the TQI of jerk $\dot{a}$ as in Eq. (8):

$$
W_{t}=c_{t}\left(\pi \lim _{T \rightarrow+\infty}\left(\frac{1}{T} \int_{0}^{T} \dot{a}^{2}(t) d t\right)\right)^{0.15}
$$

The previous equation does not consider the effect of the vehicle velocity on the indicator's formula. As a result of introducing a parameter $c_{v}$ into equation, a current value of a vehicle velocity $v$, is included in the Eq. (9):

$$
c_{v}=\frac{v}{v_{e}}
$$

where: $v_{e}$ describes a chosen reference velocity, assumed as the characteristic value of velocity (Fig. 2a). Normally this value of $v_{e}$ is selected from the range of train velocity. The parameter $c_{v}$ was introduced using derivative of the $n$-order of kinematics excitation of wheel generated by irregularity of monitoring track, as it is given in Eq. (10):

$$
w^{(n)}(t)=c_{v}^{n} \cdot w_{e}^{(n)}\left(c_{v}, t\right)
$$

where: $w^{(n)}, w_{e}^{(n)}$ are the vertical kinematic excitations of a wheel independent and dependent to train velocity, respectively. According to Eq. (10), for $n=3$ the value of a jerk $\dot{a}$ is described as in Eq. (11):

$$
w^{(3)}(t)=\dot{a}(t)=c_{v}^{3} \cdot \dot{a}_{e}\left(c_{v}, t\right),
$$

where: $\dot{a}_{e}\left(c_{v}, t\right)$ is a jerk as function of the time, registering adequately to $v_{e}$. By transforming Eq. (11) and inserting it into Eq. (8), the TQI dependent on velocity takes form of Eq. (12):

$$
W_{t_{-} v}(v)=c_{t} \cdot\left(\pi \cdot\left(\frac{v}{v_{e}}\right)^{6} \cdot \lim _{T \rightarrow+\infty}\left(\frac{1}{T} \int_{0}^{T} \dot{a}_{e}^{2}\left(\frac{v}{v_{e}} \cdot t\right) d t\right)\right)^{0.15} .
$$

In proposed monitoring system algorithm, the Eq. (12) allows to obtain similar values of track quality for various speed of train motion. It describes the impact of velocity on the proposed indicator (Fig. 2b) for a track evaluated as being in a good quality. The impact of velocity on the proposed indicator has be noted a result of early field tests and confirmed during in-service exploitation. The initial analysis of Eq. (8) was carried out for experimental data obtained during the run of

b)

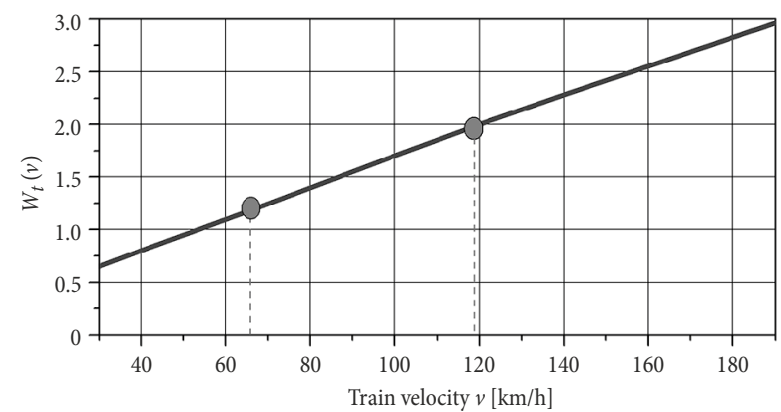

Fig. 2. Theoretical (a) and experimental (b) dependence of velocity on the TQI 
railway vehicle at two values of velocity: $v=67 \mathrm{~km} / \mathrm{h}$ and $v=119 \mathrm{~km} / \mathrm{h}$. In Fig. 2b, the points were selected in correspondence to the vehicle's velocity during the registration process and then used in analyses of measurement results. This graph was used to assess a track condition based on acceleration signal registered on axle-boxes.

\section{On-Board Measurement System}

The TQI described in previous section is used in the Rail Vehicle's and Rail Track Monitoring System. General assumptions taken into the consideration during the construction of Rail Vehicle's and Rail Track Monitoring System are as follows. First, the aim was to construct a new system, an economical and efficient alternative for on-board monitoring systems used for railway vehicle with active suspensions. Second, measurements had to be executed in compliance with standard railway engineering procedures, while using standard equipment.

The Rail Vehicle's and Rail Track Monitoring System consists of three basic subsystems (Fig. 3): On-board Subsystem, Server Data Processing Subsystem, and User Subsystem. The prototype of the on-board measurement system was developed for an in-service vehicle Electric Multiple Unit (EMU-ED74) (Fig. 4) to enable diagnosis of tracks on commercial railway lines in Poland. EMUED74 consists of four cars supported by five Jacob's bogies (Fig. 4). Fig. 5 illustrates components of the developed monitoring system. The system consists of an axel-box accelerometer for detecting track irregularities (VIS 311A piezoelectric sensor of sensitivity: $100 \mathrm{mV} / \mathrm{g}$, measuring range: $\pm 50 \mathrm{~g}$, resolution $350 \mu \mathrm{g}$ ), a Global Positioning System (GPS) receiver for detecting vehicle location, temperature sensors at bearings on each axle-box, a processing unit for signal analysis and an analog input terminal for inputting signals from each sensor to the processing unit. As it can be observed in Fig. 3, such processed signals from the sensors are transmitted by wire connection to the local data acquisition unit (LJAD frequency sampling per channel $12 \mathrm{kHz}$ at resolution of 24 bit) mounted on the vehicle. Then, signals are transmitted (the IEEE 802.3z Gigabit Ethernet Lan Standard) to a central data acquisition unit (CJAD; processing and communications unit, MOXA V2406 with Intel Atom $1.6 \mathrm{GHz}, 1 \mathrm{~GB}$ RAM), where data are filtered $(600 \mathrm{~Hz}$ low pass filter) and subjected to preliminary analysis. In a single-cycle of computing about 2000 samples ( 3 bytes per sample) from one channel are sent to the analysis, the whole process takes a few milliseconds. Algorithm calculates the value of TQI over $2 \mathrm{~ms}$. The procedure involves an initial smoothing of signal, construction of a feature vector from the smoothed acceleration signals and interpolates the vector by spline function of thirdorder. This procedure provides a data set consisting of 200 items from which the definite integral with Eq. (12) is calculated. Obtained single TQI value is temporarily recorded in CJAD, every $60 \mathrm{~ms}$. According to above procedure simultaneously from all measurement points TQI values are calculated and these values create a single data package. A data package contains: identification number of sensor, GPS localization, 1000 values of TQI per one channel, checksum to prevent the data loses. Subsequently, every 60 seconds a data package in compressed form $(94 \mathrm{~KB})$, in accordance of a Global System for Mobile Communications (GSM) gate and a GPS module is sent wirelessly by Sierra Wireless GX 400 router to a system server (Server Data Processing Subsystem), where data packages are decompressed, stored and analysed. As the result of analyses the appropriate diagnostic indicators characterising the condition of track are computed. Then, qualitative information about their condition is generated. This information is promptly sent to the relevant departments supervising the movement of vehicle and authorities responsible for technical and operational condition of a vehicle and a track. The location of a vehicle is described by geographical coordinates and is shown on the electronic map of Poland, therefore information about the condition of the track are uniquely identified with the specific place within the country area. Based on this information, it is possible to make decisions about necessary repairs, renovations or replacement of a track.

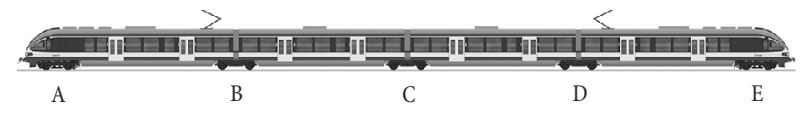

Fig. 4. ED-74 train sketch

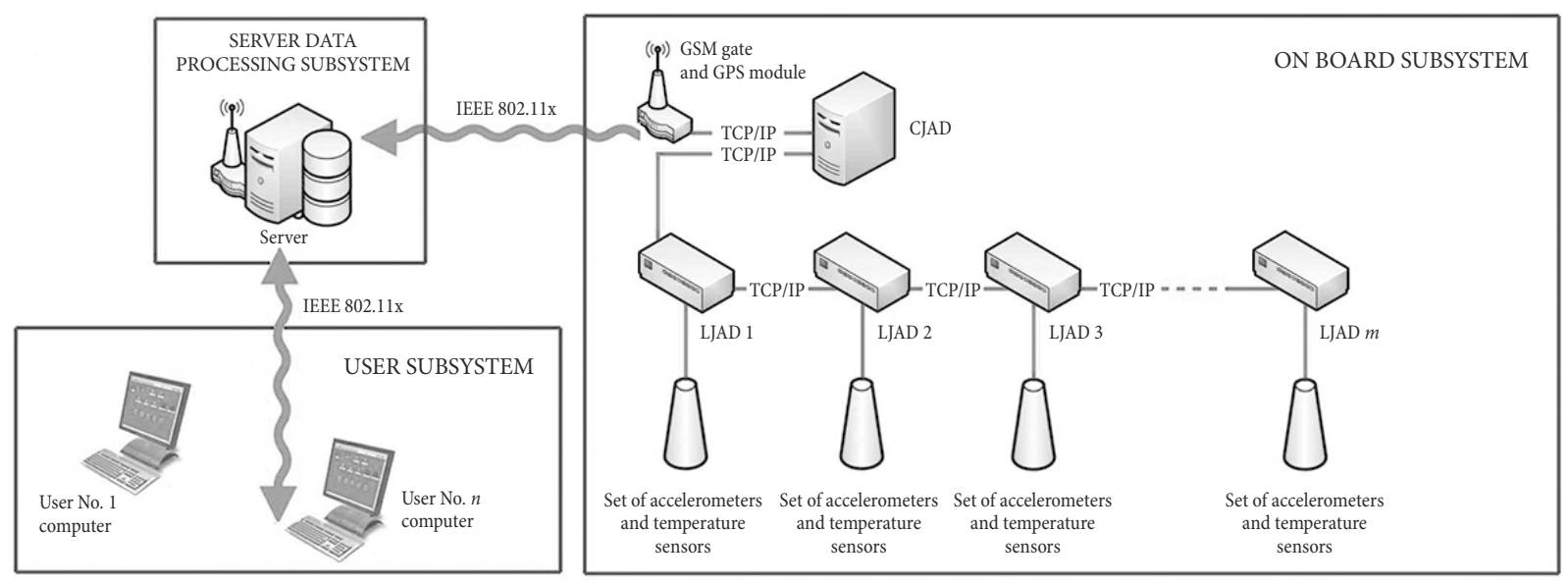

Fig. 3. Scheme of rail vehicle's and rail track monitoring system 


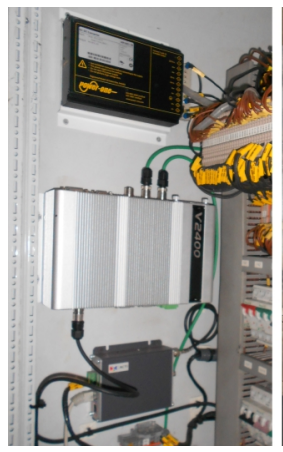

Processing unit

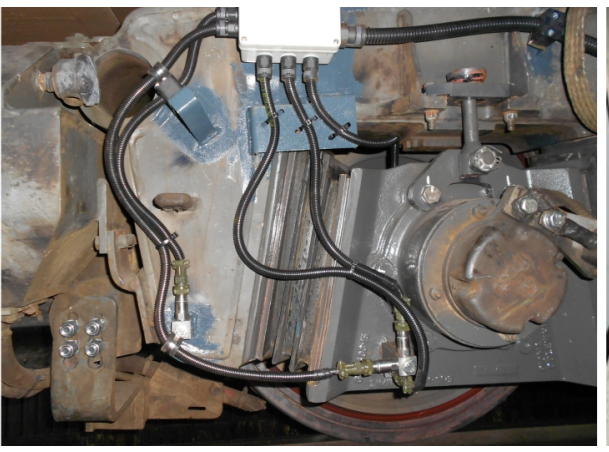

Accelerometers on axle-boxes

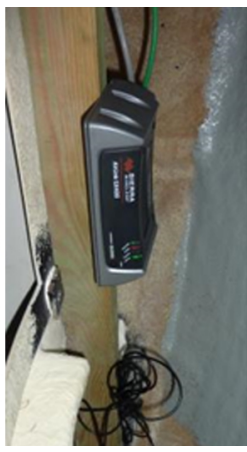

GPS receiver

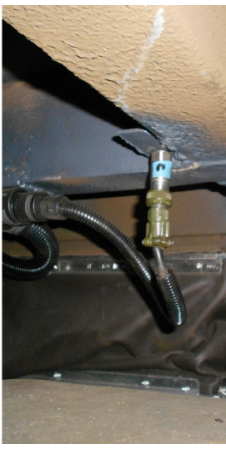

Sensor on car-body

Fig. 5. On-board track condition monitoring system

The response characteristics of an axle-box to track irregularities may vary depending on the run conditions, such as running velocity, loading and characteristics specific to vehicles; however, it can be roughly estimated by evaluating the RMS value of the axle-box and car-body acceleration in time.

The Rail Vehicle's and Rail Track Monitoring System underwent a field test and in-service exploitation. Those results are described further in the paper: field tests exploitation in Section 3. and in-service exploitation in Section 4.

\section{Field Test}

\subsection{Investigation on Test Track: Experimental Verification of Condition Monitoring Method}

Experimental studies were carried out on an experimental railway track located in Poland near the town of Żmigród (Fig. 6). The test track with the nominal length of $7725 \mathrm{~m}$ consists of six curves of different radius each. A part of track system is constructed in continuously welded rails, sometimes referred to as ribbon rails. For research purposes rails in the test track in segment $1900-3100 \mathrm{~m}$ (starting point $0 \mathrm{~m}$ is given in Fig. 6) were arranged in a jointed track technique (this technique is characterised by the fact, that there is a gap between the two conjoined ends of the rails). In the segment of the test track between $6200-7700 \mathrm{~m}$ the track was grinded to get the ideal rolling performance. This segment of the test track was taken as a reference distance for the tested monitoring system. Before main investigations, track geometry was measured by using GRAW TEP trolley (Kostrzewski, Konowrocki 2014). During the measurement, the track was divided into $300 \mathrm{~m}$ long segments. On the basis of the results synthetic coefficient $J_{\text {synth }}$ and coefficient $W_{5}$ have been determined (Table 3). This measurement allowed the authors to determine the geometry of the whole track. This gave a base to test the algorithm

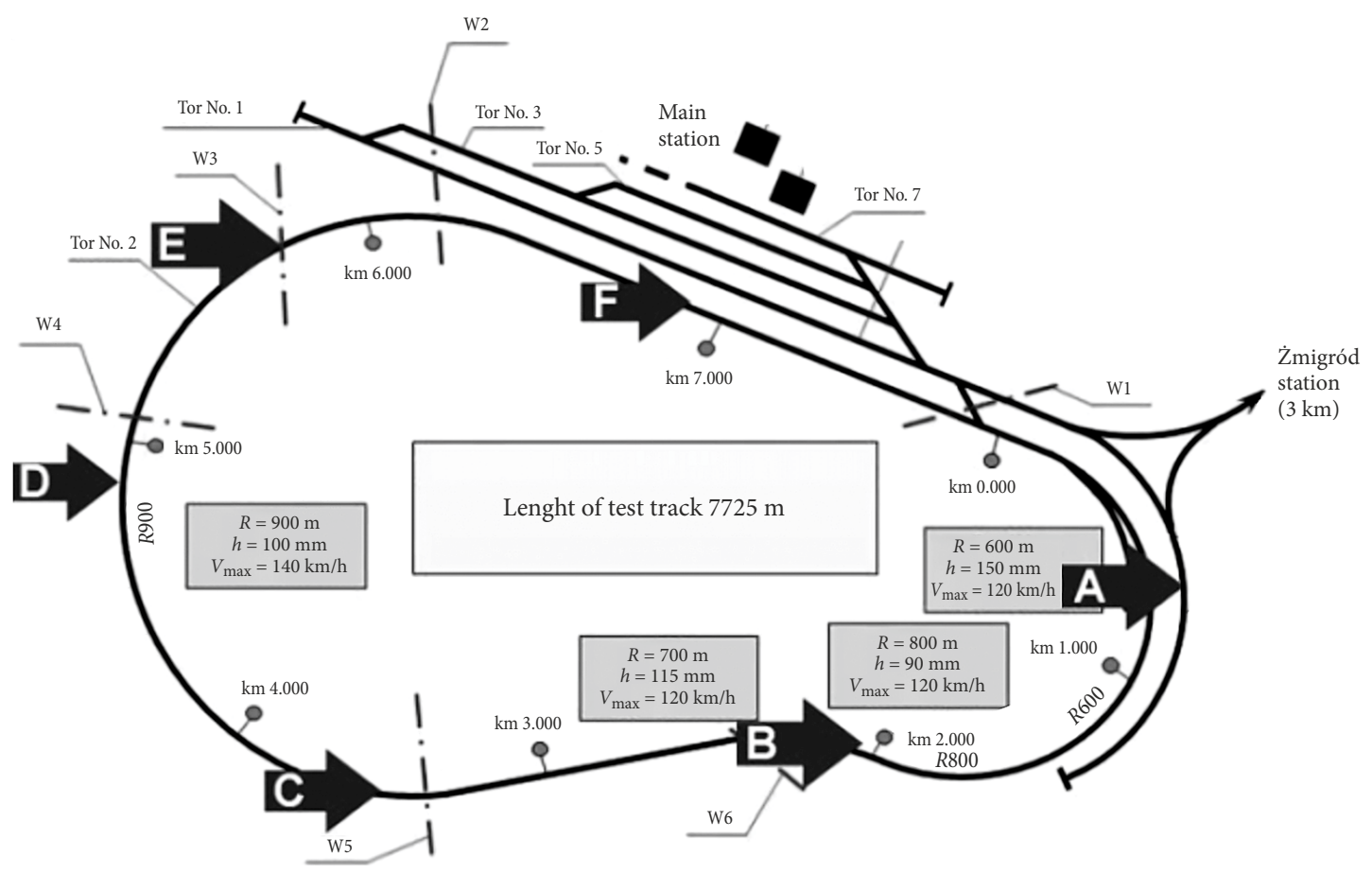

Fig. 6. Location points the start of measuring during preliminary tests at velocity $v=70 \mathrm{~km} / \mathrm{h}$ 
of the track monitoring system prototype and classification values of the TQI (see for example Fig. 7). In order to compare coefficients, the relations between TQI and $W_{5}\left(\right.$ or $\left.J_{\text {synth }}\right)$ were prepared as statistical analyses of their value. For this purpose three independent correlation coefficients (Pearson, Spearman and Kendall) were determined. In Table 4 coefficients obtained from this analysis were summarised. The correlation coefficients take values in a range from 0.79 to 0.96 . The values describe the relationship between TQI and $W_{5}$ (or $J_{\text {synth }}$ ) as a strong positive, with all data points. It confirms the correctness of the limits given in Fig. 7 .

In order to carry out the tests, the prototype of the Rail Vehicle's and Rail Track Monitoring System has been mounted on the special-purpose measuring TRV wagon. The wagon was equipped with a self-independent reference measurement system used to verify the correctness of the system prototype operation. Multiple tests at different velocity of railway vehicle (in range $40-160 \mathrm{~km} / \mathrm{h}$ ) were conducted. Some of the mentioned tests are described, with distinction of passenger cars and freight cars operation (Melnik, Kostrzewski 2012).

\subsection{Evaluation Results of Test Track}

Location of a measuring start points on the experimental track are given in Fig. 6 (these points are from $A$ to $F$ ) and these points correspond to the graphs showing TQI (Fig. 8, from $a$ to $f$, respectively) obtained from the left and right rails on the monitored test track. The results presented as waveform of the TQI confirm the condition of the track (in accordance with Table 5), measured by the GRAW TEP trolley. The highest values of the TQI (Fig. 8b), with values equal to 2.26 and 1.89 , has been reported in the segment of the jointed track between points of $B$ and $C$. The difference in the values of the TQI between the left and right side of the track occur due to the track curvature in the mentioned segment. On the length of straight part of the track between points $F$ and $A$ (Fig. 6) is taken as the base reference distance because the lowest average values of the TQI were recorded there (Fig. 8e). The experimental investigation in the test track demonstrated, that the system is sensitive not only to the quality of the rail rolling surface, but also to the high sensitivity of the tested prototype itself. This applies especially to the places where the rolling surface is not unified.

Table 3. Average values of TQIs for $300 \mathrm{~m}$ long segments of the test track computed in 3 ways

\begin{tabular}{|c|c|c|c|c|c|c|c|c|c|c|c|c|c|c|c|c|c|c|c|c|c|c|c|c|c|c|}
\hline $\begin{array}{l}\text { Test track } \\
\text { segment } \\
\text { No }\end{array}$ & 1 & 2 & 3 & 4 & 5 & 6 & 7 & 8 & 9 & 10 & 11 & 12 & 13 & 14 & 15 & 16 & 17 & 18 & 19 & 20 & 21 & 22 & 23 & 24 & 25 & 26 \\
\hline $\begin{array}{l}\text { Synthetic } \\
\text { coefficient } \\
J_{\text {synth }}\end{array}$ & 1.06 & 1.57 & 1.51 & 1.70 & 2.21 & 2.34 & 2.70 & 3.35 & 2.64 & 2.42 & 1.80 & 1.42 & 1.13 & 1.36 & 1.55 & 1.71 & 2.24 & 1.92 & 1.81 & 1.52 & 1.97 & 1.46 & 1.07 & 0.98 & 1.02 & 1.06 \\
\hline $\begin{array}{l}W_{5} \\
\text { coefficient }\end{array}$ & 0.19 & 0.29 & 0.28 & 0.31 & 0.40 & 0.43 & 0.49 & 0.61 & 0.48 & 0.44 & 0.33 & 0.26 & 0.21 & 0.25 & 0.28 & 0.31 & 0.41 & 0.35 & 0.33 & 0.28 & 0.36 & 0.26 & 0.19 & 0.18 & 0.18 & 0.19 \\
\hline TQI & 1.12 & 1.30 & 1.29 & 1.63 & 1.70 & 1.73 & 1.75 & 2.10 & 1.62 & 1.59 & 1.47 & 1.30 & 1.17 & 1.36 & 1.55 & 1.71 & 2.24 & 1.92 & 1.81 & 1.53 & 1.97 & 1.46 & 1.07 & 0.98 & 1.02 & 1.07 \\
\hline
\end{tabular}

Table 4. Comparison of correlation between TQI $-W_{5}$ and TQI $-J_{\text {synth }}$ synthetic coefficient

\begin{tabular}{|l|c|c|c|c|}
\hline Correlation methods & TQI $-W_{5}($ right $)$ & TQI $-W_{5}($ left $)$ & TQI $-J_{\text {synth }}($ right $)$ & TQI $-J_{\text {synth }}($ left $)$ \\
\hline Pearson correlations & 0.96008 & 0.91222 & 0.92570 & 0.95698 \\
\hline Spearman correlations & 0.95549 & 0.92214 & 0.92420 & 0.95599 \\
\hline Kendall correlations & 0.82866 & 0.79503 & 0.79503 & 0.83307 \\
\hline
\end{tabular}

a)

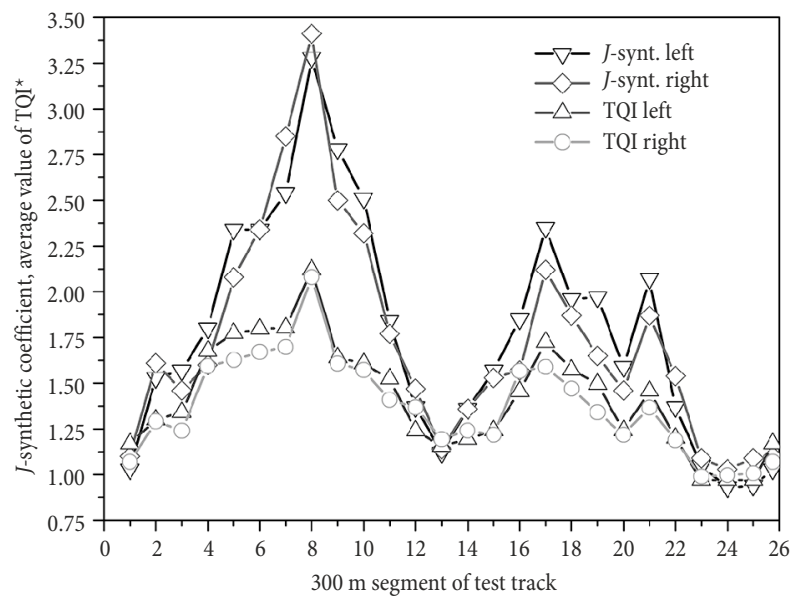

b)

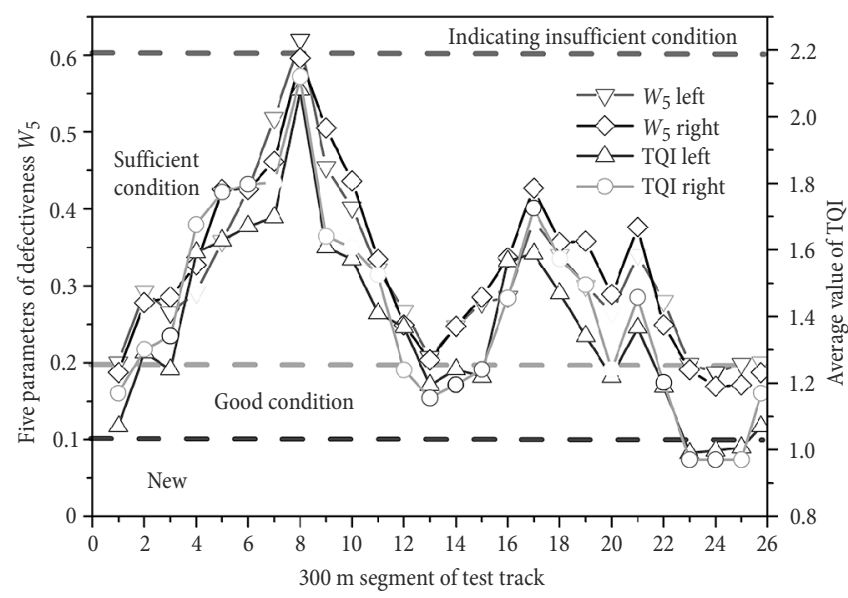

Fig. 7. Comparison of indicators of the quality of the track obtained from the test track in Żmigród (a) and classification of the TQI to quality of track (b) 
a)

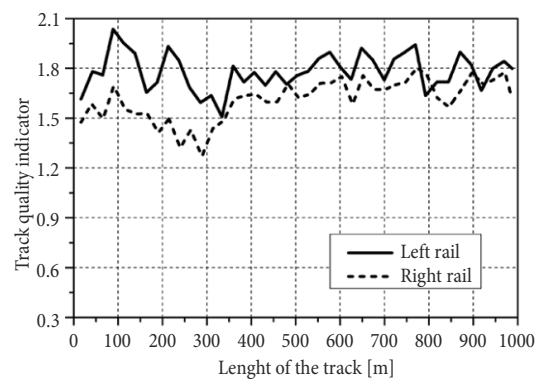

d)

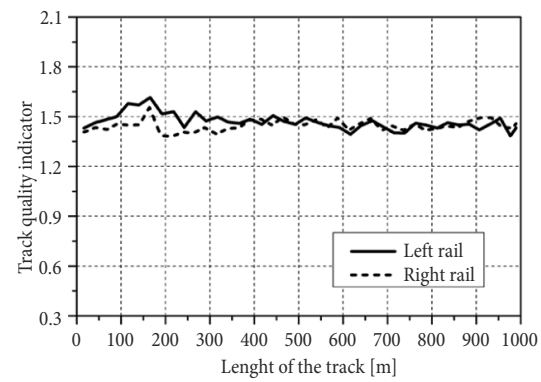

b)

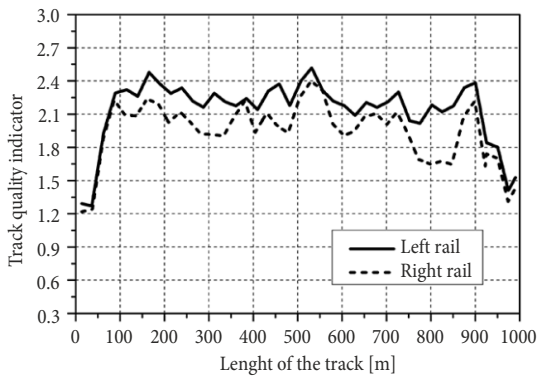

e)

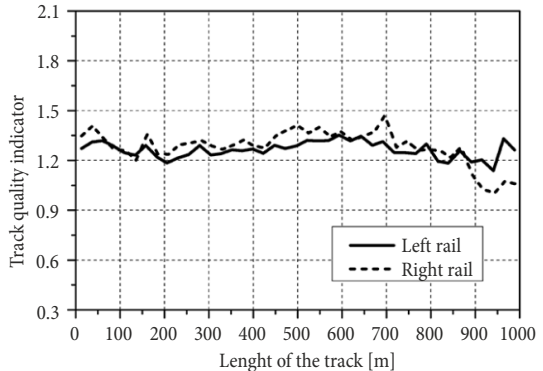

c)

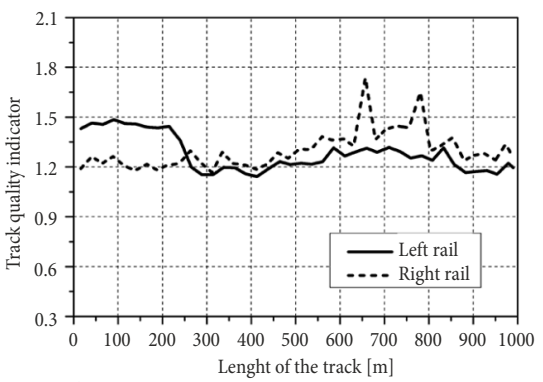

f)

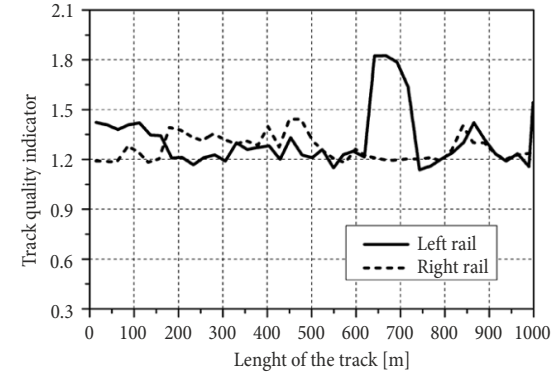

Fig. 8. TQI values obtained at the running velocity of $v=70 \mathrm{~km} / \mathrm{h}$ (for each graph, data recording started at the points illustrated on the diagram in Fig. 6)

Table 5. Track quality qualifications of railway tracks by TQI coefficient

\begin{tabular}{|c|c|c|c|c|}
\hline $\begin{array}{c}\text { Evaluation } \\
\text { of track }\end{array}$ & New & $\begin{array}{c}\text { Good } \\
\text { condition }\end{array}$ & $\begin{array}{c}\text { Sufficient } \\
\text { condition }\end{array}$ & $\begin{array}{c}\text { Indicating } \\
\text { insufficient } \\
\text { condition }\end{array}$ \\
\hline TQI value & $<0.10$ & $<0.13$ & $<2.20$ & $>2.2$ \\
\hline
\end{tabular}

Such readings were observed over the culverts along the route (Fig. 8c) and on junctions (Fig. 8f).

The proposed initial method for determining the TQI by using $W_{t}$ (Eq. (8)) showed sensitivity to changes in velocity of the railway vehicle and it has been confirmed in experimental investigations (Fig. 9a). A significant increase in velocity on the same track segment causes an increase in value of the TQI. This effect was eliminated by changing indicator $W_{t}$ into the $W_{t}(v)$ (Eq. (12)) in the algorithm that computes TQI, which

a)

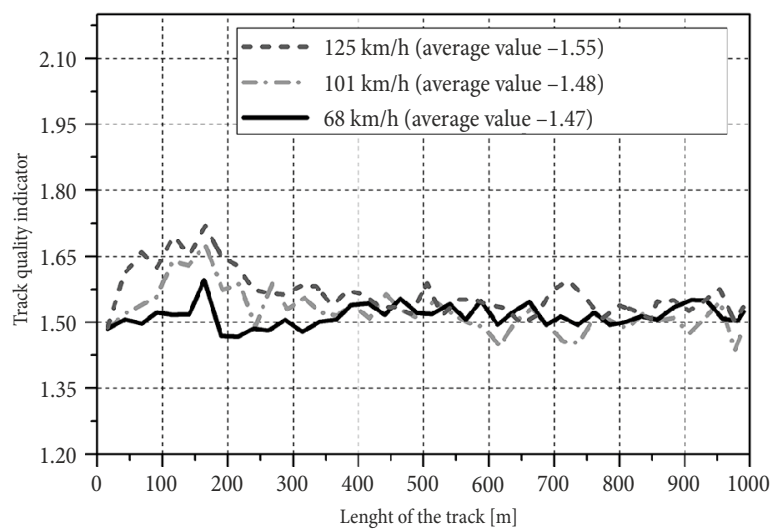

has been verified on the test track (Fig. 9b). The modification of the algorithm decreased dispersion of average value of TQI obtained on the same section of track at various runs of special-purpose measuring TRV wagon (velocity was varying from 68 to $125 \mathrm{~km} / \mathrm{h}$ ) to the level of $5 \%$.

\section{Condition Monitoring of Conventional Railway Track}

After the field test, the prototype of the Rail Vehicle's and Rail Track Monitoring System was installed in EMU-ED74. During runs of EMU-ED74 with the system prototype installed, numerous raw acceleration data signals were recorded. Almost $55 \mathrm{~GB}$ of data were registered in server data processing subsystem between 26 October 2011 and 28 September 2012. Two case studies on selected segments of track located in Polish Railway

b)

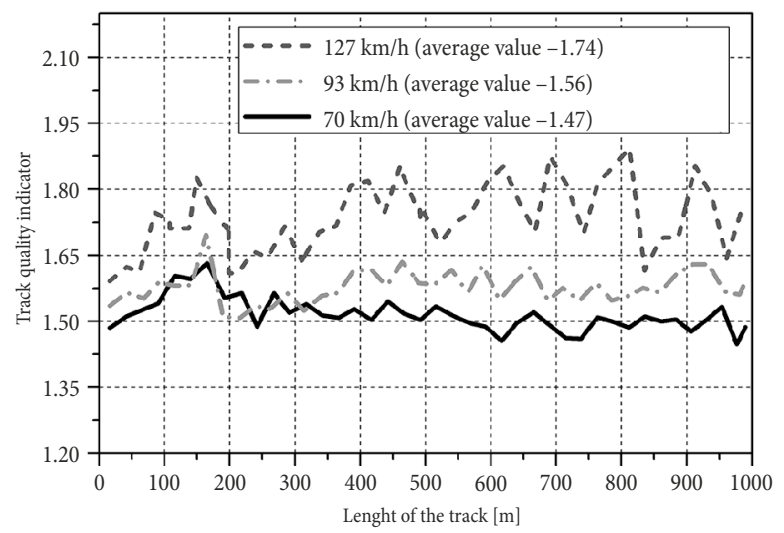

Fig. 9. Aspects of a vehicle velocity: a - the influence of velocity of railway vehicle on the TQI; $\mathrm{b}-$ the TQI independence of velocity of railway vehicle 
Lines have been chosen for analysis and described in the paper. As the first case study to be discussed in the paper, one day of runs of the EMU-ED74 was chosen. It was executed on 25 January 2012. In three charts in Fig. 10, the highest values of the TQI were registered in case of data packet No 79. This data packet was recorded in the system in the given moment of time (18:33'34") simultaneously from B-, C-, D-bogies in the town of Sochaczew after the EMU-ED74 $1 \mathrm{~km}$ long run. Data were recorded every $0.2 \mathrm{~m}$. The coordinates of the data packet No 79 indicate that it was recorded in the system about $100 \mathrm{~m}$ after passing the railway crossing on Fabryczna Street. It must be stressed here, that the values given in the charts (Fig. 10) for the data packet are values after re-sampling and statistical processing of all $1 \mathrm{~km}$ long data recording. The value course on the length of $1 \mathrm{~km}$ is shown in the separate graphs (Fig. 11). A sudden increase of the TQI occurred in the case of level crossing, railroad switch or railway turnouts. This is especially evident in case of B-bogie measurements in Fig. 11a. In Fig. 11, these points for level crossing and railway turnouts are indicated. This means that the system effectively responds to a derogation from the 'simple' course rail ('simple' as for a course rail, a railroad switch or a railway turnout). Both in case of Fig. 11 and after re-sampling and statistical processing in case of Fig. 10 no value of the TQI exceeded the boundary value of 2.0. However, the inspection of the track condition is suggested due to the fact that some values of the TQI (especially in area of level crossing) are higher than 1.6.

It was important to find packets of data in the experiment in case of which only slight deviation of velo- city occurs. What is even more important, to be compared, these data must be collected on the same route of the vehicle. Due to the fact that threshold values, mentioned in previous chapter and gained in the earlier research (by numerical analyses) are developed for a vehicle velocity between 40 and $120 \mathrm{~km} / \mathrm{h}$, the authors wanted to study the TQI's behaviour for velocity higher than $120 \mathrm{~km} / \mathrm{h}$. It was decided to analyse data gathered on a part of the route from Warsaw to Krakow. This part of the route is situated on railroad line No 4. known as Central Rail Line, between Borki village and Bógdał village. For passenger trains it is possible to run up to $160 \mathrm{~km} / \mathrm{h}$ there. As the second case study track of ca. $9 \mathrm{~km}$ length is analysed.

In order to not distort the diagram of the TQI values in function of track length, more than one diagram was introduced and presented separately. In Fig. 12 the TQI's values are given, respectively: in Fig. 12a the TQI's values concerning front right side of axle box in C-bogie, in Fig. 12c the TQI's values concerning front left side of axle box in C-bogie, in Fig. 12b the TQI's values concerning back right side of axle box in C-bogie, and at last, in Fig. 12d the TQI's values concerning back left side of axle box in C-bogie, all in the direction of ride.

It is evident that similar trend of the TQI values behaviour for nearly $9 \mathrm{~km}$ length of the track occurs, which is confirmed by all four graphs. This means that runs on two mentioned days can be compared. Nevertheless, in general this part of the track condition is considered as track of acceptable quality and good quality in the case of last $2 \mathrm{~km}$ (in correspondence to Fig. 12). a)

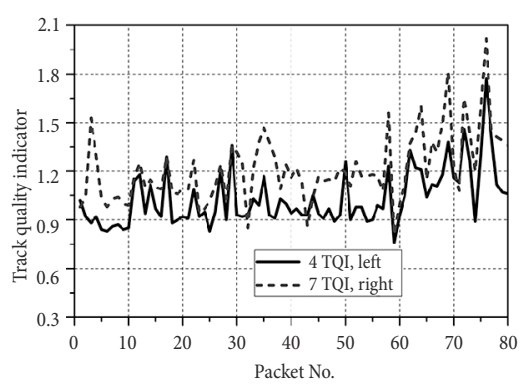

b)

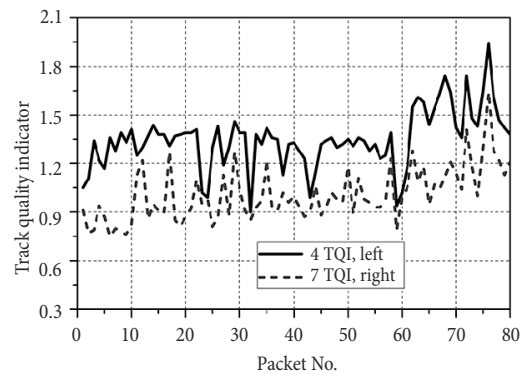

c)

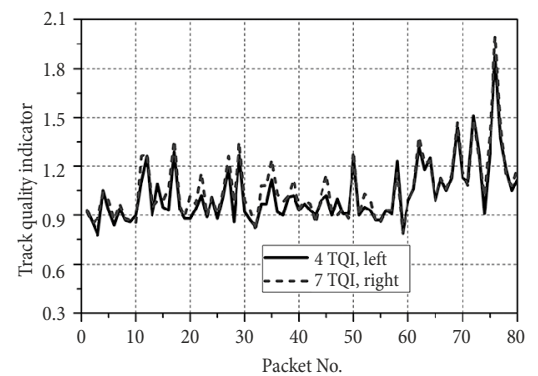

Fig. 10. Track condition chart along Warsaw-Poznan route in the case of B-bogie (a), C-bogie (b), D-bogie (c) - comparing the values of TQI obtained on the right and on the left rails

a)

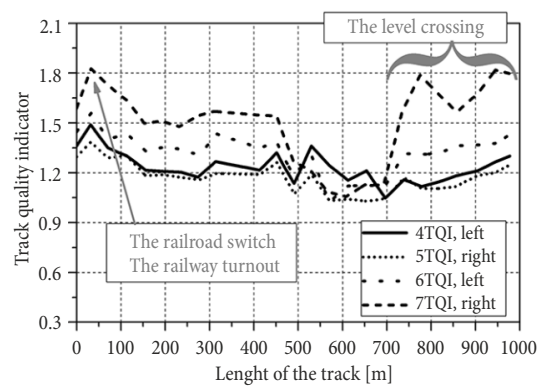

b)

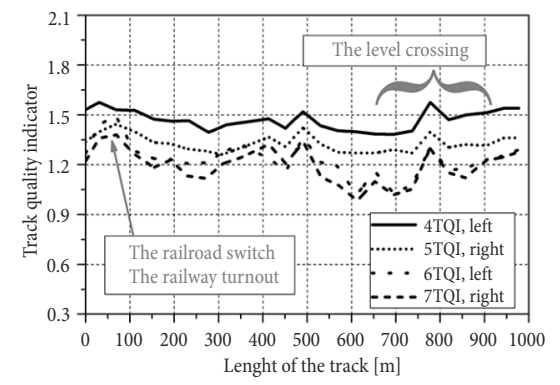

c)

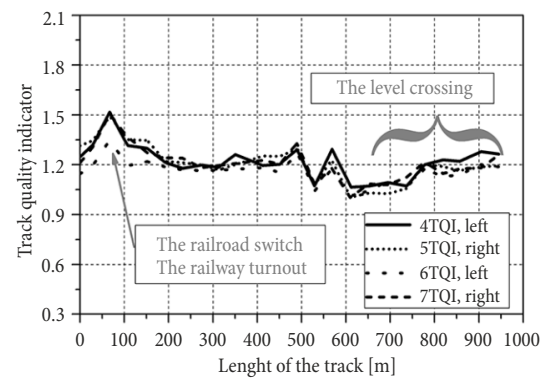

Fig. 11. Track condition chart for $1 \mathrm{~km}$ track section near Sochaczew, as recorded on 25 January 2012 in the case of B-bogie (a), C-bogie (b), D-bogie (c) - comparison of the values of TQI obtained on the right and on the left rails 
a)

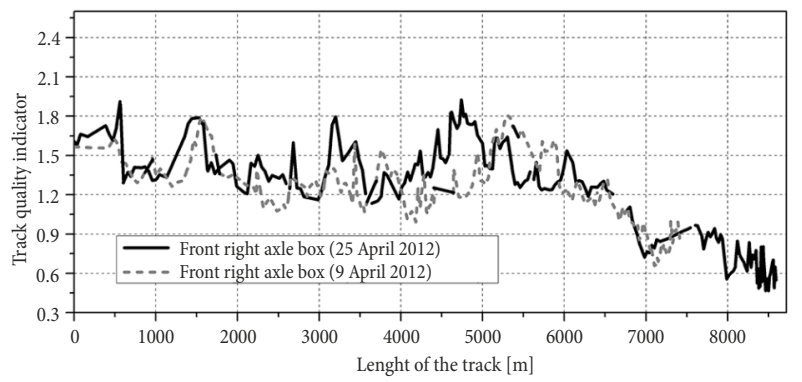

c)

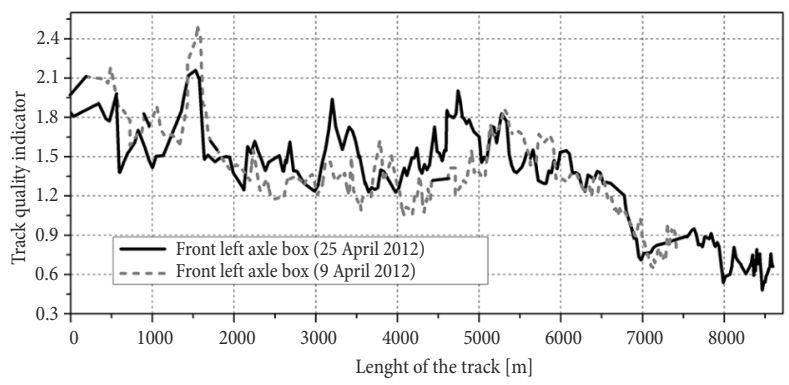

b)

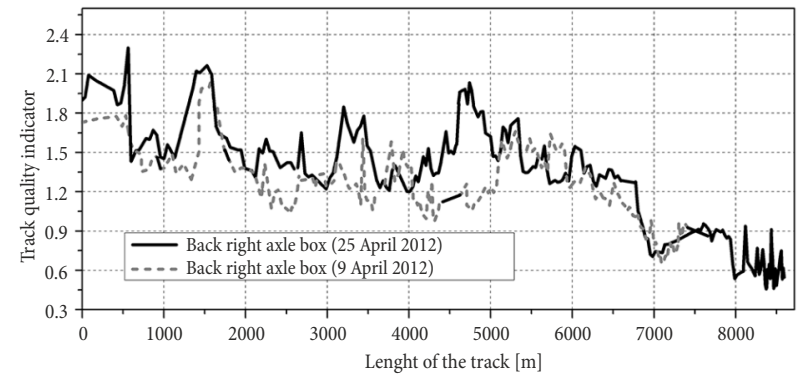

d)

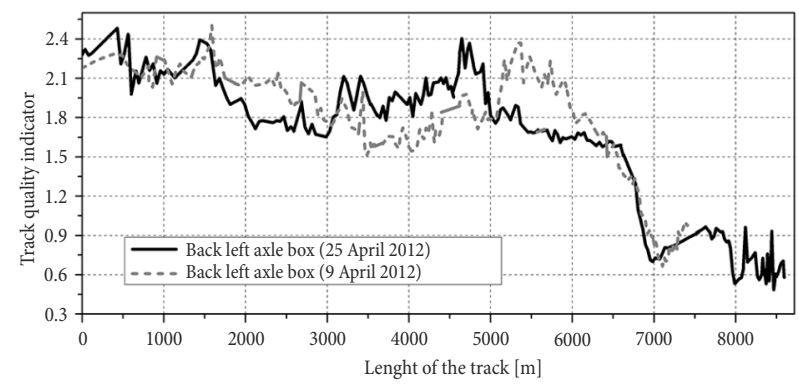

Fig. 12. The diagram for TQI

This is surrounding of Włoszczowa Północ railway station where infrastructure is relatively new (track renovation: year 2006). Central Rail Line is generally well maintained particularly in regards the condition of the track there. As it can be seen in Fig. 12, on 25 April 2012 the track condition is better than on 9 April 2012. It is due to the fact of tracks maintenance in between those dates on this line. These results indicate that the segment of the track has undergone repairs prior to the test. As a proof, for the modernisation of the line one can refer to the fact, that, on 16 November 2013, the Pendolino train reached $242 \mathrm{~km} / \mathrm{h}$ on this railway line.

\section{Concluding Remarks}

The railway vehicle/track interaction is essential for Structural Health Monitoring (SHM) and vibration control strategies for railway track management. This paper presents an application of dynamic wheel/rail interaction to assess and monitor the structural deterioration of railway track. In this paper, the monitoring system and new indicator of evaluating the track conditions have been presented. Their application in the assessment of railway quality on actual objects were studied. The proposed new indicator was referred to other, well-known and commonly used indicators of evaluating the quality of railway track. The system presented in this paper fulfils essential tasks of monitoring system related to occurrence of damage, location and severity of them. In this system, defect and degradation of the track are estimated from vertical acceleration measured on an axle-box. GPS and map matching algorithm localise the fault on track in the monitoring system. Track condition is displayed on a railway route map together with information of the location based on the position information obtained by
GPS after transmission of the processed data from system to the server.

The effectiveness of the presented method and the railway tracks condition can be assessed by considering the difference between the vibration before and after track upgrade. With the presented approach, a systematic and comparative inspection and assessment of railway tracks would make the comparison possible. Presented system can be employed to monitor the general deterioration of railway tracks.

A field test was conducted on the test track and on a commercial line in cooperation with a railway operating company Polish State Railways PKP Inc. and manufacturer of rail vehicles PESA Bydgoszcz S.A. Track irregularity was detected by vertical and longitudinal acceleration measured during the vehicle run. The field results in Polish Railway Lines showed that the longterm condition monitoring of railway track using the developed probe system gives useful information for condition based maintenance.

Continuous monitoring of the railway track in an automatic and accurate manner, along with the demonstrated capacity of damage locating in the track, has evidenced the practicality, efficiency, and stability of the developed SHM technique applied in the proposed system.

It is worth emphasizing that this paper is presumably successful in conducting a complete dynamic analysis of a railway vehicle/track system response targeted at the track condition determination. Contrary to numerous available publications in which the dynamic interaction between the railway vehicle and the track system was usually taken into consideration only from the mechanical or electrical point of view, in this paper the essential mechanical and electrical properties of both parts were 
included in the applied theoretical model. Moreover, the majority of results determined using this approach have been experimentally verified by means of the vehicle test with advanced measurement devices. Consequently, the authors hope, that they have made a contribution to substantiate the research in the field of identification of railway tracks condition. The whole subject is a serious research challenge, which deserves further studies. Moreover, identification of the type of damage in a track is one of topics for further research. The results of this investigation will be given in next paper.

\section{Funding}

This work was supported by the Polish Ministry of Science and Higher Education under Grant [POIG.01.01.0200-013/08-07] within the framework of the project Monitoring of Technical State of Construction and Evaluation of Its Lifespan - MONIT. Action Operational Programme Innovative Economy.

\section{Contribution}

Authors declare that acquisition of data was shared also by Rafał Melnik, Michał Opala, Kamil Michalski. However, conception and design of the work, analysis and interpretation of data, drafting the article or revising it critically for important intellectual content were prepared by authors themselves.

\section{Disclosure Statement}

Authors state that they have not any competing financial, professional, or personal interests from other parties.

\section{References}

Allotta, B.; D’Adamio, P.; Marini, L.; Meli, E.; Pugi, L.; Rindi, A. 2015. A new strategy for dynamic weighing in motion of railway vehicles, IEEE Transactions on Intelligent Transportation Systems 16(6): 3520-3533.

https://doi.org/10.1109/TITS.2015.2477104

Bogacz, R.; Czyczuła, W.; Konowrocki, R. 2014. Influence of sleepers shape and configuration on track-train dynamics, Shock and Vibration 2014: 1-7. https://doi.org/10.1155/2014/393867

Bogacz, R.; Grzyb, A.; Tokaj, P. 2011. Monitorowanie stanu pojazdu i toru na podstawie pomiaru przyspieszeń na korpusach łożysk zestawu kołowego, Czasopismo Techniczne 4(2-M): 11-23 (in Polish).

Bogacz, R.; Konowrocki, R. 2012. On new effects of wheelrail interaction, Archive of Applied Mechanics 82(10): 13131323. https://doi.org/10.1007/s00419-012-0677-6

BRSSOS Ltd. 2015. Track Monitoring. BRSSOS Ltd., UK. Available from Internet: http://www.brssos.co.uk/track-monitoring.html

D’Adamio, P.; Marini, L.; Meli, E.; Pugi, L.; Rindi, A. 2016. Development of a dynamical weigh in motion system for railway applications, Meccanica 51(10): 2509-2533. https://doi.org/10.1007/s11012-016-0378-2

DGSI. 2016. Track Monitoring System. DGSI, Mukilteo, WA, US. Available from Internet: http://www.slopeindicator. com/instruments/tilt-trackmonitor.php
Glösmann, P.; Kreuzer, E. 2006. Track-monitoring of wheelrail-systems, PAMM: Proceedings in Applied Mathematics and Mechanics 6(1): 303-304.

https://doi.org/10.1002/pamm.200610133

Grzyb, A. 1986. Analytical method of a rail vehicle smooth running estimation, Rail Vehicles: Selected Problems 41: $31-44$.

Huang, W.; Zhang, W.; Du, Y.; Sun, B.; Ma, H.; Li, F. 2013. Detection of rail corrugation based on fiber laser accelerometers, Measurement Science and Technology 24(9). https://doi.org/10.1088/0957-0233/24/9/094014

Kobayashi, M.; Naganuma, Y.; Nakagawa, M.; Okumura, T. 2008. Digital inertial algorithm for recording track geometry on commercial shinkansen trains, WIT Transactions on The Built Environment 103: 683-692. https://doi.org/10.2495/CR080661

Kojima, T.; Tsunashima, H.; Matsumoto, A. 2006. Fault detection of railway track by multi-resolution analysis, WIT Transactions on The Built Environment 88: 955-964. https://doi.org/10.2495/CR060931

Konop, J.; Konowrocki, R. 2013. On evaluation of the wheelsets-track interaction quality in railway engineering, $\mathrm{Ma}$ chine Dynamics Research 37(4): 61-70.

Kostrzewski, M.; Konowrocki, R. 2014. Ocena stanu wybranych odcinków toru testowego z wykorzystaniem wskaźnika jakości toru, Pojazdy Szynowe 2: 1-17 (in Polish).

Lee, J. S.; Choi, S.; Kim, S.-S.; Park, S.; Kim, Y. G. 2012. A mixed filtering approach for track condition monitoring using accelerometers on the axle box and bogie, IEEE Transactions on Instrumentation and Measurement 61(3): 749-758. https://doi.org/10.1109/TIM.2011.2170377

Madejski, J. 2004. Autonomous track geometry diagnostics system, Journal of Materials Processing Technology 157-158: 194-202. https://doi.org/10.1016/j.jmatprotec.2004.09.029

Madejski, J.; Grabczyk, J. 2002. Continuous geometry measurement for diagnostics of tracks and switches, in Proceedings of the International Conference on Switches: Switch to Delft 2002, 19-22 March 2002, Delft, Netherlands, 20 p.

Meli, E.; Pugi, L. 2013. Preliminary development, simulation and validation of a weigh in motion system for railway vehicles, Meccanica 48(10): 2541-2565. https://doi.org/10.1007/s11012-013-9769-9

Melnik, R.; Kostrzewski, M. 2012. Rail vehicle's suspension monitoring system - analysis of results obtained in tests of the prototype, Key Engineering Materials 518: 281-288. https://doi.org/10.4028/www.scientific.net/KEM.518.281

Metrom Rail. 2016. SenTrack Track Monitoring System. Metrom Rail Corporate, IL, US. 4 p. Available from Internet: http://metrom-rail.com/filebin/images/products/pdf/ SenTrack_Track_Monitoring_System.pdf

Molodova, M.; Li, Z.; Dollevoet, R. 2011. Axle box acceleration: measurement and simulation for detection of short track defects, Wear 271(1-2): 349-356. https://doi.org/10.1016/j.wear.2010.10.003

Molodova, M.; Li, Z.; Núñez, A.; Dollevoet, R. 2014. Automatic detection of squats in railway infrastructure, IEEE Transactions on Intelligent Transportation Systems 15(5): 1980-1990. https://doi.org/10.1109/TITS.2014.2307955

Montandon, J.; Mager, G. 1984. Les contrôles non destructifs appliqués aux organes du matériel roulant de la S.N.C.F., Revue Générale des Chemins de Fer 103: 69-76.

Mori, H.; Tsunashima, H.; Kojima T.; Matsumoto, A.; Mizuma, T. 2010. Condition monitoring of railway track using in-service vehicle, Journal of Mechanical Systems for Transportation and Logistics 3(1): 154-165. https://doi.org/10.1299/jmtl.3.154 
Naderi, H.; Mirabadi, A. 2006. Railway track condition monitoring using FBG and FPI fiber optic sensors, in The Institution of Engineering and Technology International Conference on Railway Condition Monitoring, 2006, 29-30 November 2006, Birmingham, UK, 198-203.

Naganuma, Y.; Kobayashi, M.; Nakagawa, M.; Okumura, T. 2008. Condition monitoring of Shinkansen tracks using commercial trains, in 4th IET International Conference on Railway Condition Monitoring (RCM 2008), 18-20 June 2008, Derby, UK. https://doi.org/10.1049/ic:20080321

Naganuma, Y.; Sato, Y. 1999. Practical use of TRASC on track state confirming cars, in WCRR'99: World Congress on Railway Research, 19-23 October 1999, Tokyo, Japan.

Oukhellou, L.; Aknin, P.; Perrin, J.-P. 1999. Dedicated sensor and classifier of rail head defects, Control Engineering Practice 7(1): 57-61.

https://doi.org/10.1016/S0967-0661(98)00163-4

RST Instruments. 2014. Track Monitoring System. RST Instruments Ltd., Maple Ridge, BC, Canada 1 p. Available from Internet: http://www.rstinstruments.com/Brochures/TrackMonitoring-System-ICB0036F.pdf

Sato, Y.; Miwa, M., 2000. Measurement and analysis of track irregularity on super-high speed train - TRIPS, International Journal of Heavy Vehicle Systems 7(1): 22-33. https://doi.org/10.1504/IJHVS.2000.004449

Stenström, C.; Parida, A.; Lundberg, J.; Kumar, U. 2015. Development of an integrity index for benchmarking and monitoring rail infrastructure: application of composite indicators, International Journal of Rail Transportation 3(2): 61-80. https://doi.org/10.1080/23248378.2015.1015220

T\&T Sistemi srl. 2009. Railway Track Quality System. T\&T Sistemi srl, Italy. Available from Internet: http://tetsistemi.com

Tsunashima, H.; Naganuma ,Y.; Matsumoto, A.; Mizuma, T.; Mori, H. 2012. Condition monitoring of railway track using in-service vehicle, in X. Perpinya (Ed.), Reliability and Safety in Railway, 333-356.

Tsunashima, H.; Naganuma ,Y.; Matsumoto, A.; Mizuma, T.; Mori, H. 2011. Japanese railway condition monitoring of tracks using in-service vehicle, in 5th IET Conference on Railway Condition Monitoring and Non-Destructive Testing (RCM 2011), 29-30 November 2011, Derby, UK, 1-6. https://doi.org/10.1049/cp.2011.0587

Weston, P. F.; Ling, C. S.; Goodman, C. J.; Roberts, C.; Li, P.; Goodall, R. M. 2007. Monitoring lateral track irregularity from in-service railway vehicles, Proceedings of the Institution of Mechanical Engineers, Part F: Journal of Rail and Rapid Transit 221(1): 89-100. https://doi.org/10.1243/0954409JRRT64

Weston, P.; Roberts, C.; Yeo, G.; Stewart, E. 2015. Perspectives on railway track geometry condition monitoring from inservice railway vehicles, Vehicle System Dynamics: International Journal of Vehicle Mechanics and Mobility 53(7): 10631091. https://doi.org/10.1080/00423114.2015.1034730

Yu, K.; Lai, C.-C.; Wu, C.; Zhao, Y.; Lu C.; Tam, H.-Y. 2014. A high-frequency accelerometer based on distributed bragg reflector fiber laser, IEEE Photonics Technology Letters 26(14): 1418-1421.

https://doi.org/10.1109/LPT.2014.2326558

Zhai, W.; Liu, P.; Lin, J.; Wang, K., 2015. Experimental investigation on vibration behaviour of a CRH train at speed of $350 \mathrm{~km} / \mathrm{h}$, International Journal of Rail Transportation 3(1): 1-16. https://doi.org/10.1080/23248378.2014.992819 